\title{
Development and Assessment of a New Project / Practice Based Civil Engineering Curriculum
}

\author{
Matthew A. Dettman, P.E. \\ Western Kentucky University
}

\section{Introduction}

Western Kentucky University is currently in the process of developing a new undergraduate engineering programs in civil, mechanical, and electrical engineering focusing on engaging the student in a project / practice based environment and preparing them for a career as a practicing engineer. This paper will discuss the process of developing the civil engineering program that began with the creation of goals for the engineering department up to the present day with a clearly defined set of programmatic objectives, outcomes and assessment tools. This paper will also discuss some of the principle lessons learned, including that the true essence of the project based curriculum is not necessarily in the list of outcomes, but in the way they are assessed and the student products generated.

Much of the work involved in the program development was based on interaction with regional constituencies, potential employers of graduates, attendance at ABET workshops, and research into effective methods of delivering a practice oriented engineering education. In addition, select universities from across the country were visited to see how they had created unique workspaces for student activities. Data was gathered for design and construction of the new engineering building at WKU, which broke ground in May of 2002 and will be ready for students in the Fall of 2004. The paper will discuss how the new facility was designed and built around the student in a project-based environment. The programs are currently scheduled for the first ABET visit in the fall of 2004. The faculty involved in the program feel that the end of the beginning has been reached and that the program is well on it's way to developing an "engaging experience" which is student focused and meshed very closely to ABET and the outcomes assessment process.

\section{History of Development of the Engineering Programs at WKU}

The initiative to establish engineering programs at Western Kentucky University has developed over a significant period of time. Discussions among campus administrators as early as 1993 established the concept as a viable direction for institutional development. Discussions with selected academic, industrial, political, and economic development leaders focused on identifying an appropriate set of goals for the initiative. The goals were expressed with respect to the desired outcomes and included the following key goals that related specifically to the curriculum and accreditation:

- Programs in engineering will be designed and implemented to be project-based and the activities of faculty and students will be focused around applied research projects for regional industries and other entities.

"Proceedings of the 2004 American Society for Engineering Education Annual Conference \& Exposition Copyright (C) 2004, American Society for Engineering Education", 
- The programs will be four-year, integrated engineering curricula rather than upper division entry programs. Such curricula will be more appropriate to the environment and would enhance retention and graduation rates of the students.

- The programs will achieve ABET accreditation in engineering that will support Western's graduates who need or desire professional registration as engineers.

Although the informal discussion with area leaders and focus groups demonstrated significant need and support for the initiative, in 1998 a more formal needs assessment was conducted. The needs assessment was conducted in support of an anticipated proposal to the Kentucky Council on Postsecondary Education for approval to offer the new degree programs.

During the latter portion of the 1998-1999 academic year, and continuing into the first half of the 1999-2000 academic year, development of the proposal for the new programs took place. The first requirement was to develop an appropriate statement of mission for the anticipated department and the individual programs. Mission statements consistent with the institutional mission and with the principles and goals established for the initiative were sought. Again, considerable exposure of the proposed missions was made to select academic, industrial, political, and economic development leaders and focus groups. This was critical in that development of the mission would define the immediate future and likely the success of the programs ${ }^{1}$. This effort resulted in the following key components of the departmental mission ${ }^{2}$ :

\section{The Department of Engineering Mission Statement:}

"The mission of the Department of Engineering is to produce, as its graduates, competent engineering practitioners."

"Realization of the departmental mission requires that the design of courses and curricula and the activities of the faculty create opportunities for students to understand and gain competence as engineering practitioners."

"Programs will be baccalaureate-driven."

"Program curricula will be project-based. Students will have sufficient opportunity to engage in project activities to support development of a clear understanding of engineering practice. The roles of students - as learners, as observers, as assistants, and as practitioners - should be supported by project activities that clearly demonstrate the practice of engineering."

"Faculty of the department will be practitioners. Scholarship of the faculty will be engineering practice conducted in the context of the departmental programs and students. Documentation of faculty productivity will be produced in the manner and form expected by the university of all faculty."

With the mission of the department established, the programmatic missions developed. In late 2000, an executive advisory board (EAB) was created for the department of engineering. This board was presented the first draft of the departmental mission. Since the programs were new, this board was critical in the development of the overall direction of the engineering programs.

"Proceedings of the 2004 American Society for Engineering Education Annual Conference \& Exposition Copyright (C) 2004, American Society for Engineering Education”, 
Once this group approved the departmental mission, The CE programmatic Industrial Advisory Board (IAB) was created. This board consisted of engineers, construction managers, directors of local utility companies, representatives of the state highway department, and others with a keen interest in the graduates of the CE program. This group spent a significant amount of time developing the civil engineering mission statement and goals, which includes the following key statements:

\section{The Mission Statement and Goals for the Civil Engineering Program}

"The mission of the civil engineering program is to prepare students for professional engineering and management positions in all phases of civil engineering projects."

"The civil engineering program will fulfill the overall mission of the department of engineering and will also meet the following goals:

- Understanding of fundamental engineering concepts that nurture problem solving abilities.

- Knowledge of basic civil engineering skills to prepare graduates for immediate productivity upon graduation.

- A background in management skills as they relate to working with financial matters as well as with people from diverse backgrounds.

- The ability to communicate ideas, processes, and designs effectively."

"The teaching philosophy of this program will focus on project based learning. This will be achieved by placing competent, practicing engineers in the classroom as professors, engaging students in the practice of civil engineering through hands-on class projects, and involving students in faculty consulting and applied research activities."

\section{Development of the Curriculum}

Expression of the mission for the CE program established a foundation for definition of an appropriate curriculum. Exemplars with similar programmatic missions and goals were identified as benchmarks and to aid in developing a "universe of topics" to be considered for the program. From this list, a set of topics consistent with the program mission and objectives were identified and coalesced into a set of courses constituting the curriculum. Comparison to benchmarks and adjustment to the guidance of the institution and $\mathrm{ABET}^{3}$ completed the curricular design process and supported sufficient course and curriculum description for the required proposals to the institution and state. The curriculum was then presented to the CE IAB for approval.

\section{Development of the Programmatic Objectives}

While the development of the mission statements was a challenge and time consuming, the real work was just beginning. The development of the $\mathrm{CE}$ objectives proved to be an even larger challenge. In order to continue an orderly developmental process, beginning in the Fall Semester of 2001 and continuing into the spring, the engineering faculty received training in the ABET process. The training program, consisting of bi-weekly sessions, were led by a WKU faculty member who was a member of the ABET board experienced in the ABET review process and

"Proceedings of the 2004 American Society for Engineering Education Annual Conference \& Exposition Copyright (C) 2004, American Society for Engineering Education" 
outcomes assessment. In addition, consultants, including Ron Miller and Barbara Olds, were utilized at strategic points in the training process to focus the activities of the faculty. The objective of the training program was to develop a common understanding of the ABET processes and a common "language" for the faculty. The planned outcome of the process was the formal expression of the program educational objectives prior to the conclusion of the 20012002 academic year. In addition to the faculty, the CE IAB also received an abbreviated training session in the ABET language and processes during the Spring 2002 meeting in preparation for participation in expressing the program educational objectives.

Critical Lesson \#1 - While all of the ABET criteria are important, understanding of the definitions of "Objectives" and "Outcomes" is critical to the process.

The following definitions were used and are considered to be consistent with the ABET definitions:

Objective - What the graduate is expected to be able to do 3 to 5 years after graduation

Outcome - What the student can do immediately after graduation

The faculty ABET training program resulted in draft statements of the program educational objectives. These statements were presented to the advisory committees in the Spring Semester of 2002 for acceptance and publication. Substantial discussion by the members of the advisory groups led to some significant changes in the draft statements and resulted in the set of civil engineering programmatic objectives presented below.

Objective 1 - Engineering Design - Graduates solve engineering problems and develop executable designs. They combine their understanding of technical, ethical, economic, and environmental issues to efficiently solve engineering problems and develop designs that are executable and realistically constructible.

Objective 2 - Project Management - Graduates include in their problem solving process the consideration of business and management principles, primarily budget, schedule, and cost. They work effectively both as an individual and on teams.

Objective 3 - Communications - Graduates have the ability to communicate, in a professional manner, their designs and processes to a diverse audience. They demonstrate effective utilization of oral, written, graphical, and visual communication skills in the context of civil engineering.

Objective 4 - Employment and Regional Relevancy - Our graduates meet the needs of regional organizations that traditionally employ civil engineers and contribute to its economic development.

Objective 5 - Professional Licensure - Our graduates pursue and achieve professional licensure

Objective 6 - Professionalism - Graduates exhibit a strong work ethic and a commitment and passion for the profession. They adapt to an ever-changing world by engaging in life-long

"Proceedings of the 2004 American Society for Engineering Education Annual Conference \& Exposition Copyright (C) 2004, American Society for Engineering Education"” 
learning beyond the workplace through memberships to professional societies and attendance of meetings and conferences. They are ethical in their approach to their work.

Objective 7 - Technical Tools - Graduates make effective use of state of the art engineering tools of their profession to efficiently execute their engineering designs and increase their productivity.

\section{Development of the Programmatic Outcomes}

With the objectives complete, the faculty proceeded to develop a set of outcomes that would ultimately allow the students to achieve the desired objectives 3 to 5 years beyond graduation. The critical issues that drove the outcome development process included:

- While ABET wants each program to ultimately achieve the "a through k" outcomes, they do not want programs simply to restate "a through k" as their own. Their intent is for programs to create a unique set of outcomes that capture the flavor of the ABET outcomes. The intent is to allow for uniqueness of each engineering program.

- To make sure the project-based mission is captured in the development of the outcomes.

Both of these issues proved to be very difficult to overcome. While the idea of not restating a-k sounds good, it is very difficult to do. Several drafts of the outcomes revealed that the outcomes were simply being combined, or just reworded. In addition, it was difficult to show the true essence of the project-based nature of the curriculum. These problems were both solved with the learning of Critical Lesson \#2:

\section{Critical Lesson \#2 - The uniqueness of the curriculum and the true essence of project based learning is in the data collected, not in the wording of the outcomes.}

Once this lesson was learned, a set of outcomes was developed and the focus was not on making it look different than the ABET a-k, but to craft them in such a way that the design projects and the unique activities of the project based learning environment could capture the mission of the program as well as be used to assess the outcomes. In addition, there was less concern with the fact that the CE outcomes looked a lot like the ABET outcomes with only minor differences. Research of many other schools revealed that programmatic outcomes generally do look like ABET a-k outcomes.

With that, the following set of outcomes were developed:

Outcome 1 (Physical Analysis) - Civil Engineering graduates will demonstrate the mathematical, experimental, and engineering science skills required in the civil engineering problem solving and design process.

Outcome 2 (Professional Analysis) - Civil Engineering students will demonstrate recognition of the non-technical issues important in the civil engineering design process, including recognition of the importance of society and contemporary issues in their professional practice, constructability, economics, availability, and aesthetics.

"Proceedings of the 2004 American Society for Engineering Education Annual Conference \& Exposition Copyright (C) 2004, American Society for Engineering Education” 
Outcome 3 (Synthesis) - Civil Engineering students will be able to synthesize physical and professional analyses in their designs.

Outcome 4 (Teamwork) - Civil Engineering students can work effectively in multi-disciplinary teams to identify, develop, and execute the solution to a problem.

Outcome 5 (Management) - Civil Engineering students can effectively participate in the management of a project.

Outcome 6 (Communication) - Civil Engineering students demonstrate effective communications skills.

Outcome 7 (Regional Relevancy) - Civil Engineering students are able to find employment, primarily regionally, with organizations that traditionally employ civil engineers.

Outcome 8 (Life Long Learning) - Civil Engineering students demonstrate development of habits associated with life long learning.

Outcome 9 (Professionalism / Ethics) - Civil Engineering students show common characteristics of professionalism and knowledge of ethical behavior.

Outcome 10 (Engineering Tools) - Civil Engineering students can effectively use state of the practice civil engineering technical tools.

\section{Assessing the Outcomes}

The heart of the ABET process is the assessment of the programmatic outcomes. At this point in the development of the program, the faculty were ready to develop a plan for assessment of the outcomes. While all involved agreed the outcomes appeared to be good, there was a great deal of discussion and confusion among faculty as to what the outcomes actually meant and how they were defined. For example, in Outcome 10, what is a "civil engineering technical tool" and what would count as "effectively use". It was finally agreed upon that the student work or other data that is collected to assess the outcome ultimately defines the outcome. This made the process of agreeing upon the meaning of each outcome much easier because most faculty generally agreed upon the types of work that would be collected for assessment.

\section{Critical Lesson \#3 - Let the activities associated with the student work collected ultimately define the outcome.}

This lesson is very similar to Lesson \#3. The student work collected should drive the definitions of the outcomes and the assessment process. In outcome 10, what "engineering tools" are and what is "use effectively" will be reflected in the work collected. For example, in a project based learning environment, it is expected that real-world type of engineering projects will be a critical part of the design experience. Real engineering projects are generally managed in such a way that schedule and budget are established. Therefore, it would be expected that in this outcome,

"Proceedings of the 2004 American Society for Engineering Education Annual Conference \& Exposition Copyright (C) 2004, American Society for Engineering Education"” 
student work that utilizes project management software and methodologies would be present and assessed. Lesson \#2 allowed the faculty to freely write outcomes knowing that the student work collected would ultimately define each outcome. Lesson \#3 was the process of actually choosing the student work that clearly matched the outcome to be assessed in a project-based environment. In a research driven environment, it would be expected that a similar outcome would exist, but the student work collected would look very different and highlight the use of very different engineering tools.

The current assessment plan used was based on the Assessment Matrix ${ }^{4}$ developed by Barbara Olds and Ron Miller of Colorado State University and from the "Stepping Ahead" guide developed by Gloria Rogers and Jean Sando ${ }^{5}$. It is essential that the assessment process be used to "close the loop" and to make sure that if deficiencies are exposed in the assessment process, that a mechanism exists to make the necessary adjustments. The overall plan with the objectives and outcomes were in place is as follows:

1. Establishment of Performance Criteria for Each Outcome - What should the student know and be able to do?

2. Evaluation Methods - What information will be collected to assess the outcome?

3. Target Results - What result is the goal?

4. Timeline - When will it be collected?

5. Feedback - What will be done with the results?

\section{Critical Lesson \#4 - It is not necessary to assess each student ${ }^{6}$.}

It was determined that the plan should focus on assessing a group of students, not assessing each student. The first draft of the assessment plan consisted of collecting and assessing a great deal of student work. Upon review of the draft and with some feedback from Dr. Miller, the decision was made to collect a much smaller set of student work with the idea that a cross sectional profile is enough. While more data is often better, the realities of faculty workload and potential burnout exist. For example, if technical writing is being assessed and lab reports from 3 different courses are being collected, the question must be answered "is different information being assessed in the different courses?". If all 3 reports are assessing the same thing, then 1 is enough. If a student can write effectively about a soil mechanics laboratory project, it is reasonable to expect that the same student can write effective about a fluid mechanics laboratory project.

The following is a detailed look at the assessment plan for Outcome 1, which is essentially the engineering science and experimentation outcome.

\section{Outcome One}

Civil Engineering graduates will demonstrate the mathematical, experimental, and engineering science skills required in the civil engineering problem solving and design process.

"Proceedings of the 2004 American Society for Engineering Education Annual Conference \& Exposition Copyright (C) 2004, American Society for Engineering Education"” 


\section{Performance Criteria}

The CE faculty have developed the following performance criteria for the math, experimentation, and engineering science skills for this outcome. Each student should be able to do the following:

Experimentation

1. Perform the experiment and/or collect the data in accordance with the applicable standard,

2. Perform the necessary calculations or data reduction to achieve the desired result,

3. apply the results to a practical situation

Engineering Science and Mathematics

1. Prepare the appropriate physical model of the problem

2. Apply and perform the correct mathematical analysis

3. Present the final result in the appropriate manner

\section{Evaluation Methods:}

1. Experimentation - CE faculty evaluations of selected student work in CE 161 (surveying lab), CE 411 (soils lab), ME 331 (deformable solids lab).

2. Engineering Science Analysis - CE faculty evaluations of selected student work in CE 316 (equipment and methods), CE 382 (structural analysis), CE 410 (soil mechanics).

3. Additional Data - Scores on the FE exam, GPA's of CE students in calculus and physics, and results of the WKUSES questionnaire, senior exit surveys, focus group of regional CE employers to evaluate selected student work.

\section{Courses for student work evaluation:}

\begin{tabular}{|l|l|l|}
\hline \multicolumn{1}{|c|}{ Course } & Description of selected work & \multicolumn{1}{c|}{ Assessment Method } \\
\hline CE 161 - Surveying & Surveying Field Book & Experimentation Rubric \\
\hline $\begin{array}{l}\text { CE 316 - Equipment } \\
\text { and Methods }\end{array}$ & Selected Student Exam & Engineering Science Rubric \\
\hline $\begin{array}{l}\text { CE 382 - Structural } \\
\text { Analysis }\end{array}$ & Selected homework or exam & Engineering Science Rubric \\
\hline $\begin{array}{l}\text { CE 411 - Soil } \\
\text { Mechanics }\end{array}$ & $\begin{array}{l}\text { Selected exam problem } \\
\text { (settlement) }\end{array}$ & Engineering Science Rubric \\
\hline $\begin{array}{l}\text { CE 411 - Soil } \\
\text { Mechanics Lab }\end{array}$ & Selected Laboratory Report & Experimentation Rubric \\
\hline $\begin{array}{l}\text { ME 331 - Strengths } \\
\text { of Materials Lab }\end{array}$ & Selected Laboratory Report & Experimentation Rubric \\
\hline
\end{tabular}

"Proceedings of the 2004 American Society for Engineering Education Annual Conference \& Exposition Copyright $\left({ }^{\circ} 2004\right.$, American Society for Engineering Education" 


\section{Target Results}

The target result for both the experimentation and engineering science is an average result of 3 with less than $10 \%$ achieving 1 . The rubrics have been designed such that the descriptors given for the desired score represent a student who generally performs the required work correctly, with at most 1 or 2 minor procedural errors that impact the final result only slightly. We also included scoring criteria that addresses the actual presentation of the final result. It was determined through discussions among faculty as well as with the IAB that it is important that not only should the students be able to get the right answer, but they should know how to present the answer in the appropriate way reflecting the accuracy of the process used and the data used in that process. For example, it would be inappropriate to express the final result accurate to 3 decimal places if the inputs used were only accurate to one decimal place at best.

The supporting data collected includes GPA's from math and science courses outside of the CE curriculum, which will provide background data for the necessary skills. For example, if students are having a difficult time developing the appropriate math model, but the overall grades in the pre-requisite math courses are acceptable, then we must determine where the disconnect exists. This will aid in the loop closure process for the demonstration of proficiency.

Focus groups of students, alumni, and regional employers will also be convened. The desired result will be that the general consensus of the focus groups is that the students are adequately prepared to perform the necessary engineering science analysis and experimentation expected of an entry lever engineer.

\section{Timeline}

This data will be collected each year for the first 3 graduating classes. At that point, the data collection process will be reduced to every other year. As indicated earlier, more data is better, but the process must be manageable considering the workloads of the faculty.

\section{Feedback}

Each of the learning outcomes has a faculty "champion" who is responsible for being sure that the assessment of the outcome is on track according to the timeline. S/he is also responsible for collecting and analyzing the data on a systematic basis. The faculty member prepares a brief report that includes a description of the method(s), where in the curriculum the outcome is assessed (for program assessment purposes), and a brief report of the findings. The report is presented at a summer faculty ABET meeting and, based on the findings, recommendations made for program improvement. The faculty champion is responsible to follow-up and report on the success of the improvements. With a small department there is the advantage that $100 \%$ of the faculty are involved in every step, as opposed to a smaller percentage who simply report to the rest of the group.

The following rubrics have been developed to perform the assessment of student work for outcome 1:

"Proceedings of the 2004 American Society for Engineering Education Annual Conference \& Exposition Copyright $(\mathrm{C} 2004$, American Society for Engineering Education” 


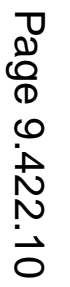




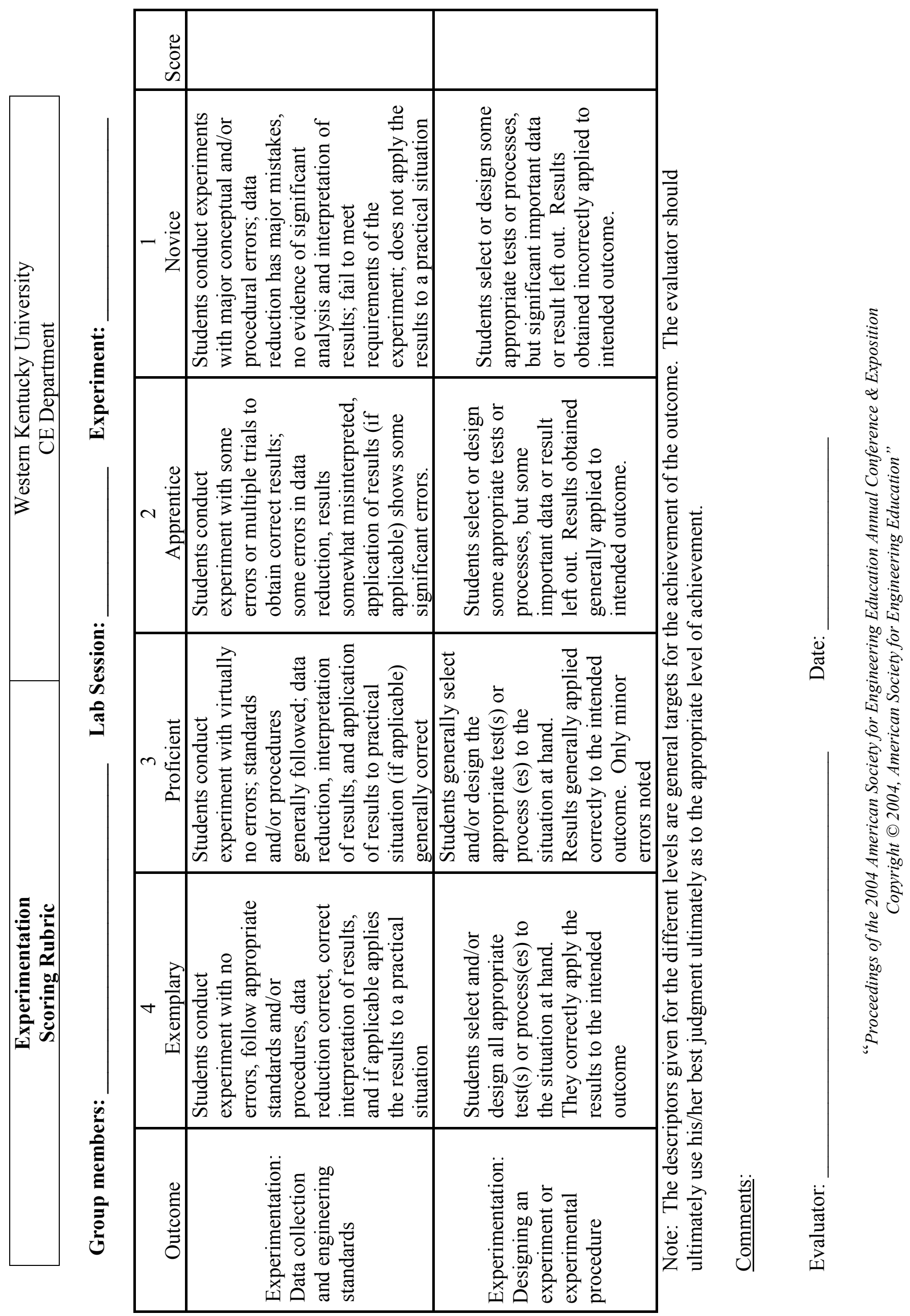




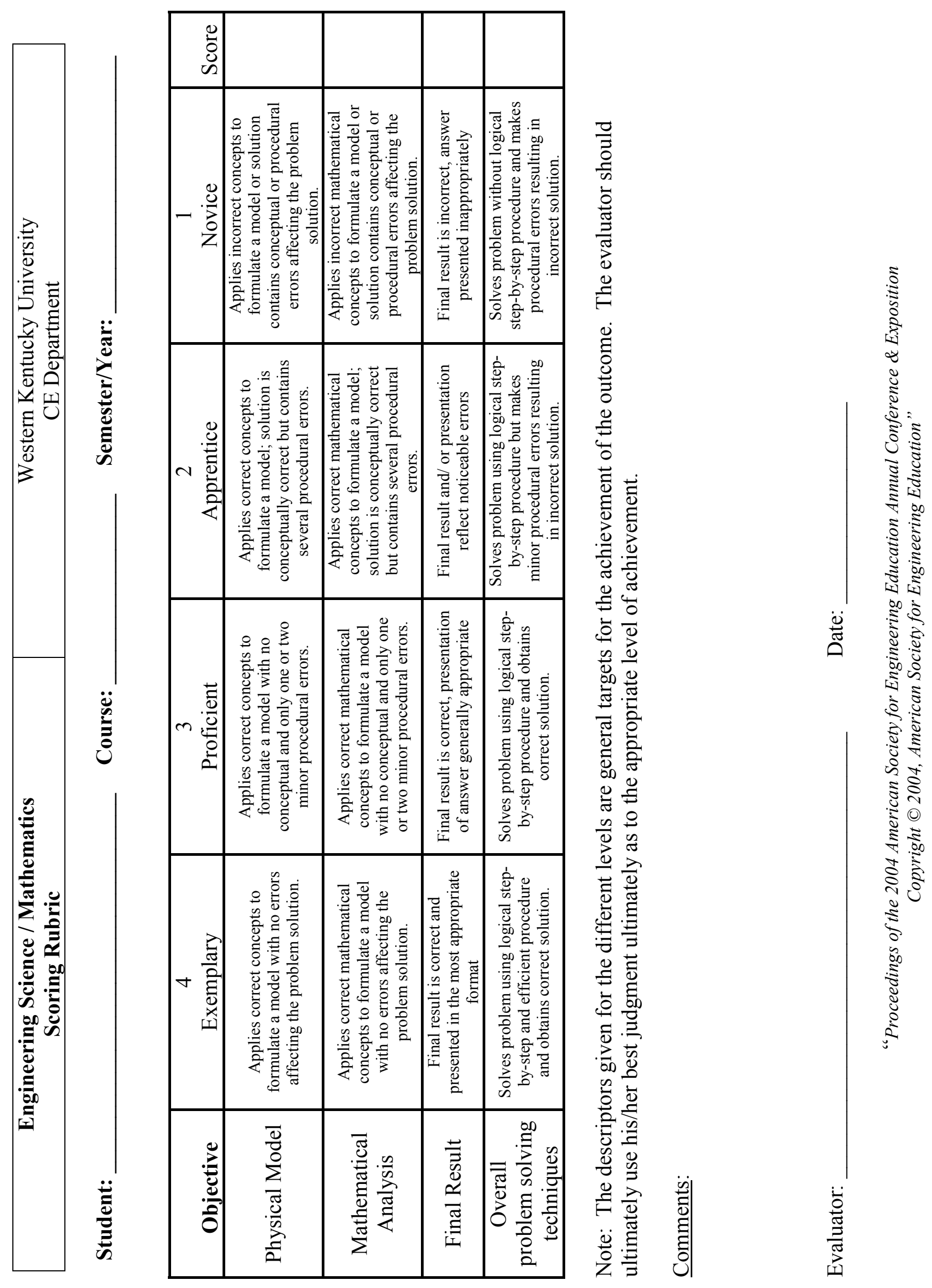


The assessment of the other outcomes is essentially the same. In the case of assessing student work, a rubric was developed for each outcome. Some outcomes required no collection of student work with only data such as FE exam results being collected.

\section{Course Peer Review Process}

In addition to the official ABET process, the Engineering Department has implemented an internal quality control program for courses. As required by ABET, each course has a clear and concise set of course outcomes. The course outcomes are consistent with program outcomes in that they consist of what the student should be able to do upon completion of the course. At the end of each semester, the students fill out an assessment form rating their ability to perform each outcome. The faculty member teaching the course also assesses the students based on their own perception of the students ability to perform each outcome based on the results of student work. The faculty member then assembles a report discussing the course and providing recommendations for improvement of the course. The peer reviews for each course are then reviewed and discussed by the entire faculty. This process provides a continuous feedback loop for each course. It has proven thus far to be a very effective way to get feedback from colleagues on courses and allows the students to be an integral part of program improvement.

A peer review file is kept for each course which will include the syllabus, the peer review form, notes from the peer review meeting, and samples of student work ranging from high to low. This file also becomes the course file to be exhibited during the ABET visit.

\section{The Engineering Building}

Upon approval at the state level of the new engineeing programs, the university president immediately began the process of securing funding for a new facility. Several members of the engineering faculty began to research the best type of facility for the delivery of project / practice based engineering education. Several universities were visited, photographed, and videotaped to provide ideas in how to engage the students in engineering projects. An architectural firm with significant experience in university engineering laboratory buildings was hired to design the structure. During this process, word came from the state legislature that only $50 \%$ of the requested budget would be funded. The decision was then made to include only those aspects of the building deemed most critical to the mission. The building centered on the programmatic student project rooms and the Integrated Applications Laboratory (IAL). The project rooms were designed with state of the art technology to provide the students with adequate computing power for all of their projects. A projection system was also included to help them prepare for the strong oral communication and presentation requirement of the curriculum. Large tables and ergonomically correct chairs were ordered to allow project teams to layout drawings as needed.

The IAL is considered to be the showcase of the building. This facility will contain all of the necessary space, tools, crane system, large scale testing equipment, power, data acquisition, and much more so that the students are fully equipped to design, test, and build their engineering projects.

"Proceedings of the 2004 American Society for Engineering Education Annual Conference \& Exposition Copyright (C) 2004, American Society for Engineering Education" 
After these 2 spaces were designed, faculty offices and the other laboratories critical to the engineering programs were included. A large "engineering yard" was situated outside of the IAL with large overhead doors providing access. This space was designed for the present as well as the future. The building is expected to go on-line in the summer of 2004 in time for the ABET accreditation visit.

\section{Conclusion}

The development of the new civil engineering program at WKU has been a long and challenging process. One advantage was that the program was created from a clean slate which allowed for full inclusion of the current ABET processes into it's creation. While many schools have had to fit their existing programs into the new ABET process, WKU has been able to fully mesh the process of outcomes assessment into the creation of the program. This experience has shown that the true uniqueness and quality of this project / practice based program is ultimately in the student work. The faculty are confident that the feedback from sources such as employers, FE and PE exam results, and the alumni will show that the mission of the program is being fulfilled and that graduates of the WKU Civil Engineering program have truly been prepared for careers as engineering practitioners. In the fall of 2003, the majority of the first cohort of graduating seniors took the FE exam with a $100 \%$ pass rate. While this piece of data alone is only the beginning, it is a good indication that the program is on the right track.

\section{$\underline{\text { References }}$}

1. Olds, B.M., and R.L. Miller, "Lesson Learned in Developing and Implementing a Program Assessment Plan", International Journal of Engineering Education, Vol. 18, No. 2, pp. 217-234, 2002.

2. Western Kentucky University Undergraduate Catalog, 2003 - 2005

3. ABET, Engineering Criteria 2000: Criteria for Accrediting Programs in Engineering in the United States, Accreditation Board for Engineering and Technology, http://www.abet.org/criteria.html

4. Olds, B.M., and R.L. Miller, "An Assessment Matrix for Evaluating Engineering Programs", Journal of Engineering Education, April 1998, pp 173-178.

5. Rogers, Gloria and Jean Sando, "Stepping Ahead: An Assessment Plan Development Guide", Rose-Hulman Institute of Technology, Terre Haute, Indiana, 1996.

6. Rogers, Gloria, "EC 2000 and Measurement: How Much Precision is Enough?", Journal of Engineering Education, May 2000.

\section{Biographical Information}

Matthew A. Dettman is the James D. Scott Professor of Civil Engineering. He is currently the civil engineering program coordinator at Western Kentucky University and his primary areas of interest are in Geotechnical Engineering and Construction Quality Control. He was named Civil Engineering Educator of the Year in the state of Kentucky in 2002, and currently serves on the Governors Council for Earthquake Risk Reduction.

"Proceedings of the 2004 American Society for Engineering Education Annual Conference \& Exposition Copyright (C) 2004, American Society for Engineering Education" 